\title{
Mobile Phone as a Friend for Elderly in Various Health Aspects
}

\author{
Rajshree Chandrakar ${ }^{1}$, Dr. A. R. Joglekar ${ }^{2}$ \\ ${ }^{1}$ Assistant Professor, department of Home-Science, Bhilai Mahila Mahavidayalya, Bhilai, Chhattisgarh, India \\ ${ }^{2}$ Professor of Home Science, Govt. D. B. P. G Girls College, Raipur, Chhattisgarh, India
}

\begin{abstract}
Elderly people are the most vulnerable people as they prone to several physiological, psychological and social problem associated with disabilities and diseases. They feel helpless in various fields like conveyance, communication, security, purchasing food, contacting people, hospital etc. and faced various problems in our society which make their life unhealthy. Mobile is new, easy to operate, potable and faster effective technology, which make their life healthy and friendly. To examine the use of mobile phone by elderly for above health related evidences a study was conducted on 140 elderly residing in Durg, Bhilai province in which 70 male and 70 female were selected. A designed questionnaire was used to collect data. The obtained data were analyzed in percentage and finding shows that of all elderly people $80 \%$ Male and 73\% used mobile day to day for various purposes, $70 \%$ Male and 55\% Female for revealing information, $33 \%$ male and $50 \%$ female for sharing health related inquiries with their friends and children. Elderly considered that mobile is a supporting device for them and recommended for mHealth services for better, health monitoring and management of elderly.
\end{abstract}

Keywords: Elderly, Mobile, Health Aspects

\section{Introduction}

Ageing is a phase of life and a biological process, According to medical dictionary it is a process of becoming older i.e A process which is effected by genetically and environmental conditions, Shekhar,C (2013). Government of India adopted national policy on older person defines "senior citizen" or "elderly" as a person who is 60 years an above in January 1999. The population of ageing is rapid growing in India. After China ( 230 million). India was the second largest elderly population of world. Goel P.K.,et al(2013).It was expected that elderly population will increased to 179 million by 2026 Balan urugan, J. Dr. Ramnatirtam G.(2012)

During aging elderly people faces various physiological problem like diabetes, blood pressure, hypertension asthma, Gastric osteoporosis, arthritis etc. The degenerative effects diminished vision, cognitive decline, memory, speech ability to calculate, hearing loss (Pattison $\mathrm{M}$ and Stedmon, A.,(2006) Elderly people were also facing service and facilities problem related with health like communication, transportation, conveyance at hospital , purchasing medicine $\&$ foods, informing, security, health policy \& insurance etc.

Due to modernization, urbanization nuclear family culture and mechanization nobody has time to spend and help to elderly regarding health. In order to cope with this problem new and innovative technology mobile assured to make their life faster, better, safer, effective and healthy Joe J. Demiris G.( 2013). The World Health Organization (2002) has proposed a model of active ageing by optimizing opportunities for health participation in order to enhance the quality of life.

WHO also investigated for elderly eHealth to support the status of mHealth including (emergency toll free telephone service, mobile telemedicine, appointment reminder, health call center) . In America $69 \%$ of older adult aged 65 are using mobile phone Zickuhr, k. (2012).

By adopting these mobile technology the elderly themselves feel happy and empowered and became active by managing their health, education and share with their family and friends about health and security concerns, monitoring own health Deter,D., et al(2008), Providing information and getting social support Skeels MM., Unruh, KT., Powell, C., Pratt, W.(2010). High growth of mobile phone and its potential gives a platform for improving and strengthening health of elderly Jeo Jonathan et al (2013). Along with rapid growth of mobiles and facing health problem it is important to examine present evidences of use of mobile in relation to health purpose.

\section{Methodology}

Keeping this view in mind following study was conducted in Durg Bhilai city of Chhattisgarh, with basic objective to examine the frequency of use of mobile phone among elderly for their health related aspects .A total 140 sample 70 male and 70 female of age group of 60 years and above were selected from east, west $\&$ north south and central zone of Durg- Bhilai city. A self designed questionnaire was used to elicit the required data on different health issues.

\section{Result and Discussion}

Table 1: Age-wise distribution of Male and Female elderly

\begin{tabular}{|c|c|c|c|c|c|c|}
\multicolumn{9}{c|}{ person } \\
\hline \multirow{2}{*}{ Age (years) } & \multicolumn{2}{|c|}{ Male } & \multicolumn{2}{c|}{ Female } & \multicolumn{2}{c|}{ Total } \\
\cline { 2 - 7 } & $N=70$ & $\%$ & $N=70$ & $\%$ & 140 & $\%$ \\
\hline $60-64$ & 35 & 50 & 38 & 54 & 73 & 52.14 \\
\hline $65-69$ & 20 & 28.57 & 23 & 32.85 & 43 & 30.71 \\
\hline $70-74$ & 12 & 17.4 & 7 & 10 & 19 & 13.57 \\
\hline $75-80$ & 3 & 4.28 & 2 & 2.85 & 5 & 3.57 \\
\hline Total & 70 & 100 & 70 & 100 & 140 & 100 \\
\hline
\end{tabular}


International Journal of Science and Research (IJSR)

ISSN (Online): 2319-7064

Index Copernicus Value (2015): 78.96 | Impact Factor (2015): 6.391

Table 2: Type of mobile phone used by elderly person

\begin{tabular}{|c|c|c|c|c|c|c|c|c|}
\hline \multirow{2}{*}{} & \multicolumn{2}{|c|}{ Simple Mobile } & \multicolumn{2}{|c|}{ Smart Phone } & \multicolumn{2}{c|}{ Not use } & \multicolumn{2}{|c|}{ Total usage } \\
\cline { 2 - 9 } & No & $\%$ & No & $\%$ & No & $\%$ & No & $\%$ \\
\hline Male & 42 & 60 & 19 & 27.14 & 9 & 12.85 & 61 & 87.14 \\
\hline Female & 37 & 52.85 & 17 & 24.85 & 16 & 22.85 & 54 & 77.7 \\
\hline Total & 79 & 56.42 & 36 & 25.71 & 25 & 17.8 & 115 & 82.14 \\
\hline
\end{tabular}

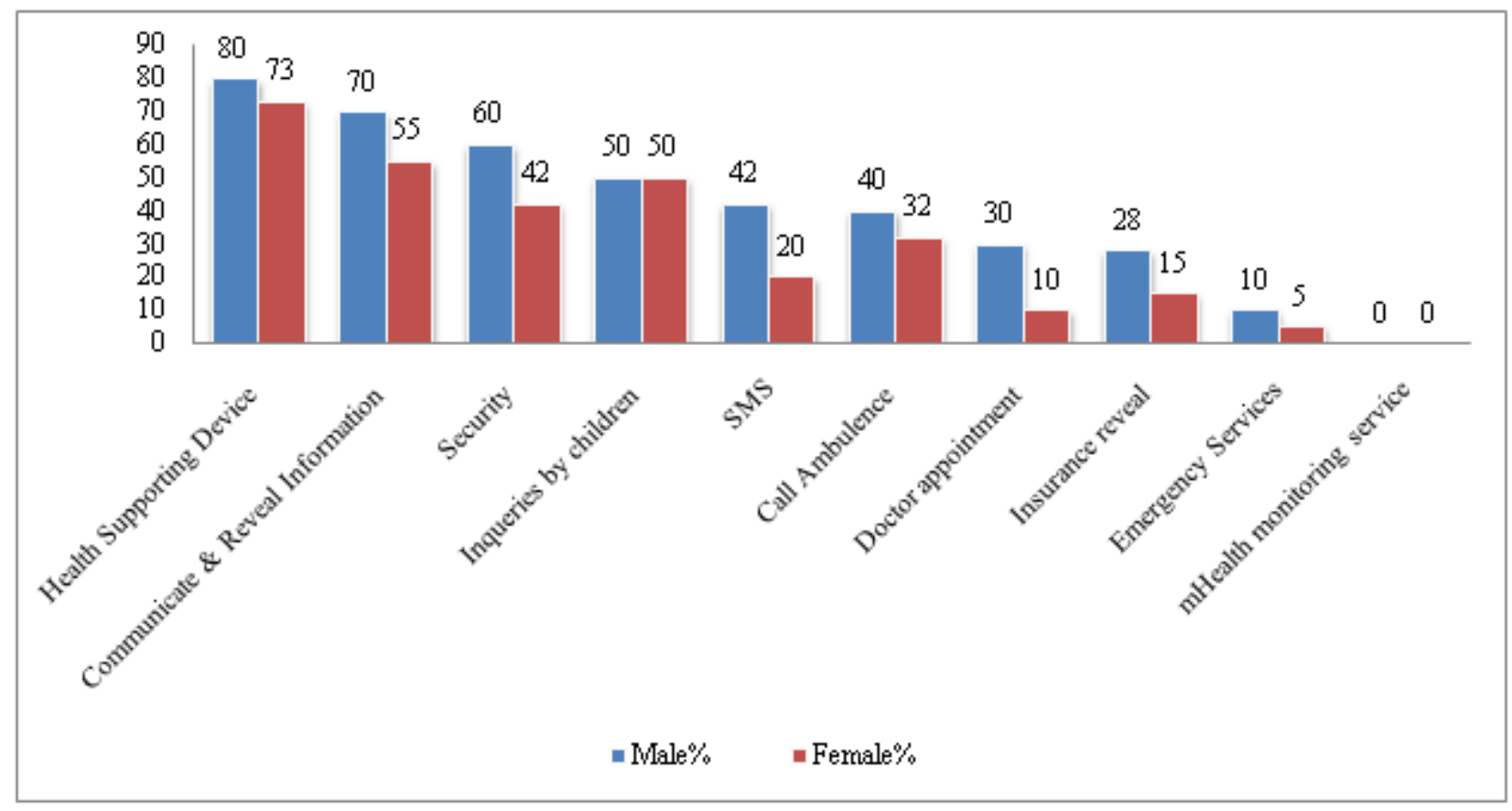

Figure 1: Mobile use in different Health aspects

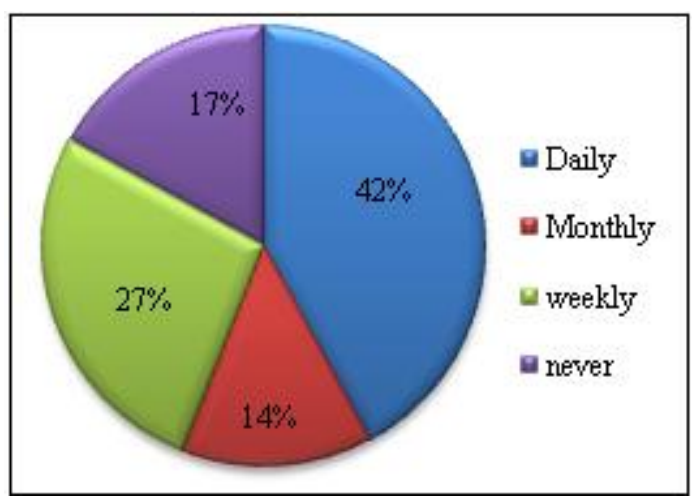

Figure 2: Percentage of time period spent on mobile

1) In our study $80 \%$ male and $73 \%$ female elderly considered that mobile is a supporting device in all health aspects but they prefer only simple mobile not smart phone because of complicated technology.

2) $70 \%$ male and $55 \%$ female used mobile to communicate by sharing and receiving thoughts i.e. feeling regarding health, disabilities, Doctor's report, information while walking, leaving home before travelling etc.

3) $60 \%$ male and $42 \%$ female feel secured physically, psychologically and socially by using mobile.

4) Children of $50 \%$ elderly people inquires about their food habit, problems they face ,money, servant services etc. and instruction for their security and well being. By Answering these elderly feel satisfied.

5) Results indicate that $42 \%$ male and only $20 \%$ female receiving \& forwarding messages regarding insurance (28\% male \& $15 \%$ female). reports, health illness, social contract and banking which make them physically, socially \& economically healthy. Few of them using whats App.

6) $40 \%$ elderly and female (32\%) called ambulance services (108) provided by C.G. Govt.

7) It was found that only $30 \%$ male gave preference to take appointments for health checkup of doctors which was followed by $10 \%$ female.

8) Only $10 \%$ male and 5\% female followed emergency toll free service but lack of awareness was found.

9) There was no mHealth monitoring services found in private and government hospital in Durg Bhilai City. West, D. also reported in lowest rate of $m$ health was adopted Africa while north south America and southeast Asia. Mobile technology is helpful in monitoring to control deluge fever have found in pilot project.

\section{Conclusion}

Mobile phone is a faster, safer and supporting device for health aspects of elderly. With rapid growth of population it provides an excellent opportunity to utilize mobile in various health related aspects in the life of elderly. The technology act as friends for various purpose like communication, education, alertness, security, hospital, instruction given by doctors, children, relatives \& friends regarding health.

It was observed that male were more aware than female about mobile usage, since smart phones involves complex technology very few elderly people of Durg Bhilai were using smart phone, there was lack of awareness about emergency toll free service and mhealth services. Special training, counseling and awareness were needed for elderly

\section{Volume 6 Issue 1, January 2017


women. It was suggested to the government and private hospital to enables mhealth service for proper health management of elderly.

\section{References}

[1] Balamurugan, J., Dr. Ramnathirtham, G.,(2012) Health Problem of Aged population International Journal of Research in social science 2(3) 140 ISNN 2249-2496.

[2] Detmer,D., Bloomrosen,M., Raymon,B.,Tang,P. (2008) Integrated personal health record transformative tools for consumer -centric care BMC informatics and decision making 8:45, (Pubmed 18837999)

[3] Goel PK,Gary. Sk.,Singh,JV., Bhatanagar.M.,Chopra.H.,Bajpai.S.k,(2013) unmeet need of the elderly in rural population of meerut. India Journal of community medicine,3(4)163.

[4] Joe J.,Demiris, G.(2013),Older adult and mobile phone for health. A review Journal of Biomedical Informatics 46-947-954

[5] pattison,M.\& stedmom,. A(2006) Inclusive design and human factor : Designing mobile phone for older user Psychology Journal 4,267-284.

[6] Shekhar,C.,Koul p.kourt T.(2013). old age and adjustment, Gender Different in institution alized and non-institutionalized elderly 2(2)31-36

[7] situation analysis of the elderly in India (2011) central statistics office ministry of statistics and program office ministry of statistics and Program implementation government of India Page-3

[8] Skeels,MM., unruh,KT., Powell,C.Pratt,W.(2010) Proceeding of the $28^{\text {th }}$ international conference on human factor computing system, catalyzing social support for breast cancer patient ACM Press P.173

[9] WHO (2011)mHealth new horizons for health through mobile technologies Global observatory for eHealth series volume 3 WHO library cataloging in publication data ISBN $978924156450 w w w . w h o . i n t$

[10]Zickuhr,K.,Madden,M(2011).Older adults and internet use (internet) 2012 